This item was submitted to Loughborough's Research Repository by the author.

Items in Figshare are protected by copyright, with all rights reserved, unless otherwise indicated.

\title{
Variation between manufacturers' declared vibration emission values and those measured under simulated workplace conditions for a range of hand- held power tools typically found in the construction industry
}

\section{PLEASE CITE THE PUBLISHED VERSION}

http://dx.doi.org/10.1016/j.ergon.2007.10.023

\section{PUBLISHER}

(C) Elsevier

\section{VERSION}

AM (Accepted Manuscript)

\section{LICENCE}

CC BY-NC-ND 4.0

\section{REPOSITORY RECORD}

Rimell, Andrew N., Luca Notini, Neil J. Mansfield, and David J. Edwards. 2019. "Variation Between Manufacturers' Declared Vibration Emission Values and Those Measured Under Simulated Workplace Conditions for a Range of Hand-held Power Tools Typically Found in the Construction Industry". figshare. https://hdl.handle.net/2134/7547. 
This item was submitted to Loughborough's Institutional Repository (https://dspace.lboro.ac.uk/) by the author and is made available under the following Creative Commons Licence conditions.

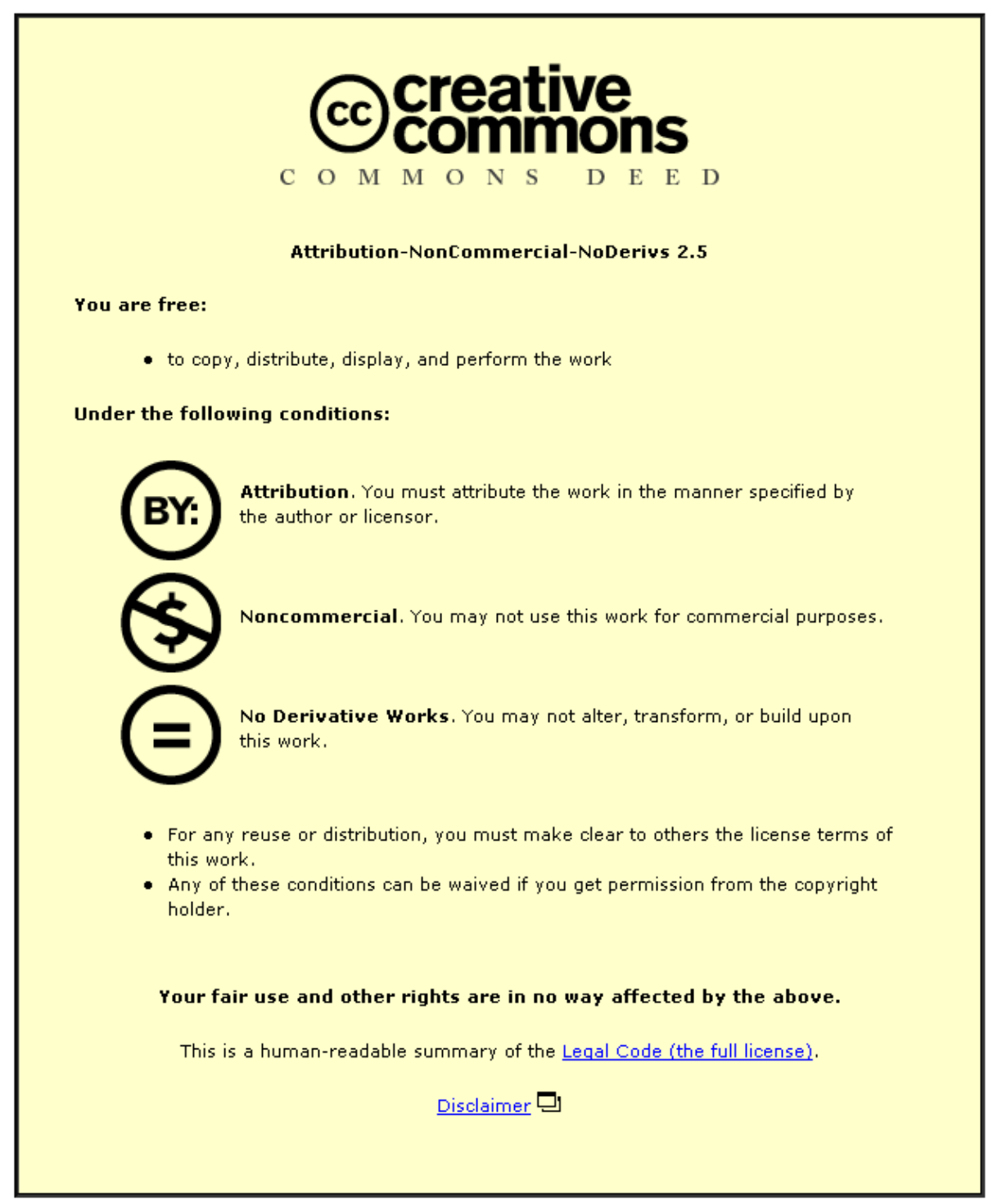

For the full text of this licence, please go to: http://creativecommons.org/licenses/by-nc-nd/2.5/ 


\title{
Variation between manufacturers' declared vibration emission values and those measured under simulated workplace conditions for a range of hand-held power tools typically found in the construction industry
}

\author{
Dr Andrew N Rimell ${ }^{a}$, Dr Luca Notini ${ }^{a}$, Dr Neil J Mansfield ${ }^{a^{*}} \&$ Dr David J Edwards ${ }^{b}$ \\ ${ }^{a}$ Department of Human Sciences / ${ }^{b}$ Department of Civil and Building Engineering \\ Loughborough University \\ Loughborough
}

LE11 3TU

UK

\begin{abstract}
A.N.Rimell@lboro.ac.uk, L.Notini2@lboro.ac.uk, N.J.Mansfield@lboro.ac.uk \& D.J.Edwards@lboro.ac.uk "Corresponding author
\end{abstract}

\begin{abstract}
Tool manufacturers are required to declare the vibration emission of their hand-held power tools in order to sell them within Europe. To enable comparison between different manufacturers, tests are carried out in accordance with the relevant test code (such as those defined in the ISO 8662 and EN 60745 series). These tests may be carried out in artificial circumstances which do not necessarily correctly predict the vibration emission that would be obtained in the workplace and often underestimate the magnitude of the vibration. In practice, tools are used with a range of inserted tools on different materials, resulting in a range of vibration emission values for a given tool. CEN Technical Report, CEN/TR 15350 provides multiplication factors to enable an estimate of the workplace vibration emission to be obtained from the manufacturers' data.
\end{abstract}


This paper compares the manufacturers' declared vibration emission values with those measured for the public-domain OPERC HAVTEC database. The OPERC measurements have been made according to ISO 5349 using simulated workplace conditions, with a range of inserted tools for each machine tested. A total of 656 tool/attachment combinations are presented from 105 different tool models, covering a wide range of applications typically found within the construction industry. The measured data is compared with the manufacturers declared emission value, with and without the multiplication factors given in CEN/TR 15350 .

It was found that, in general, the manufacturers' declared values underestimated the workplace vibration emission, whereas the multiplication factors given in CEN/TR 15350 overestimated the workplace vibration emission.

\section{Relevance to industry}

This paper discusses 656 measurements made on 105 models of power tools commonly found in industry. The data and analysis presented may assist practising managers in the assessment of exposure to vibration of their employees, thereby ensuring that they remain within the limits specified by the EU Physical Agents (Vibration) Directive and ANSI S2.70 (2006).

\section{Keywords}

Vibration exposure, ISO 5349, ANSI S2.70, power tools, hand-transmitted vibration 


\section{Introduction}

Every day many thousands of workers are exposed to hand-transmitted vibration in their workplace through the use of hand-held power tools ranging from small percussion drills to large pneumatic breakers. Continued usage of high-magnitude vibrating tools can result in Secondary Raynaud's Disease where the fingers become blanched (Mansfield 2005), also known as Vibration White Finger, a part of Hand-Arm Vibration Syndrome, HAVS (Dong, Rakheja et al. 2001, Wasserman 1985). In 2005, the European Union Physical Agents (Vibration) Directive (2002) came into force setting limits on the vibration exposure to which a worker may be subjected in a working day. The lower threshold, the Exposure Action Value (EAV), is the level at which the employer is required to make changes to minimise both the exposure and risk: this may include a change of tool or a change of working practice. The higher threshold, the Exposure Limit Value (ELV), is the maximum allowable exposure for an employee in a working day. For hand-transmitted vibration, the Directive specifies the EAV and ELV vibration magnitudes in terms of an 8-hour equivalent frequency weighted r.m.s. (EAV $=2.5 \mathrm{~m} / \mathrm{s}^{2} \mathrm{~A}(8)$, ELV $=5 \mathrm{~m} / \mathrm{s}^{2} \mathrm{~A}(8)$ ). The Vibration Directive has been paralleled in the US with ANSI S.2.70 (2006) which uses identical criteria for risk evaluation (Reynolds 2006).

Under the European Union Machinery Directive (1998; currently forming the basis of relevant European law, pending the implementation of the 2006 amendment in June 2008), tool manufacturers are required to provide 'declared' vibration emission values for their tools, measured according to the appropriate test code, if the weighted r.m.s. acceleration is greater than $2.5 \mathrm{~m} / \mathrm{s}^{2}$ (manufacturers must state if it is less than $2.5 \mathrm{~m} / \mathrm{s}^{2}$, but do not need to publish the actual value). Where there is no suitable test code, manufacturers must describe the measurement methodology used. Commonly used test codes are specified by the EN 60745 (EN 60745 2003) and the ISO 8662 (ISO 8662-1 1988) family of standards, which comprise several parts, each part being specific to a particular tool type. Some of the tests (for example ISO 8662-4 (1994) for angle grinders) are not representative of actual working practice, whereas others are closer to actual tool usage (for example ISO 8662-6 (1995) for impact drills). The values obtained by ISO 8662 often differ from the exposure values that would be obtained if measured in the workplace according to ISO 5349-1 (2001) as required by the Physical Agents (Vibration) Directive, thus making it difficult to 
estimate a worker's exposure to vibration from the manufacturer's declared emission values. For example, if the vibration for a two handled tool is measured at only one of the handles, it may be the case that the other handle has a greater magnitude of vibration. Also, the data is often reported for only a single-axis and it is possible that another axis has greater vibration. The relevant standards committees are currently working to improve these standards, with the aim of each declared value providing the $75^{\text {th }}$ percentile value of exposures for a tool operator.

In order to provide guidance on the use of declared emission data, CEN (European Committee for Standardization) have produced a technical report, CEN/TR 15350 (Mechanical vibration - Guideline for the assessment of exposure to hand-transmitted vibration using available information including that provided by manufacturers of machinery, 2006) containing multiplication factors intended to transform manufacturers' declared values to those measured by the method described in ISO 5349-1 (2001). The multiplication factors vary with tool type, usage and power source (multiplication factors for the tools presented in this paper are shown in Table 1). The technical report states that if a tool type or application is not explicitly listed then a multiplication factor of at least 1.5 should be applied and that where a manufacturer declares a value of less than $2.5 \mathrm{~m} / \mathrm{s}^{2}$, a value of $2.5 \mathrm{~m} / \mathrm{s}^{2}$ should be used. The report also states that the multiplication factors are intended to give a general indication of the vibration exposure rather than an exact numeric value, particularly for pneumatic tools. Hewitt and Smeatham (2005) and Hewitt and Nelson (2005) state that in the absence of better information, multiplication factors may be used for basic risk assessment, and they suggest that a multiplication factor of 2 for all tools will result in the estimate of vibration exposure either being equal to or exceeding $61 \%$ of that measured using an ISO 5349-1 (2001) based measurement. However, Hewitt's method may result in the vibration exposure for some tools being greatly overestimated and, therefore, the tools being rejected unnecessarily as part of a risk assessment, placing an unnecessary burden on industry. It is therefore suggested by the authors of this paper, that measurements conforming to a work-place type measurement, such as ISO 5349-1 (2001), be used whenever available for that tool and attachment. 
It is reported that in the UK construction industry nearly 500,000 workers are subject to vibration above the EAV (HSE 2003), and in response to demand from the industry itself (Edwards, Holt 2005), the trade association OPERC (www.operc.com) have established a freely available online database of in-use tool emission values based on independent tests (Mansfield 2006). The tests have been carried out within the guidelines of ISO 5349-1 (2001) and ISO 5349-2 (2002), using simulated work site conditions. The database has been supported by the major tool manufacturers, industry groups (for example, the UK Major Contractors Group, MCG) and hire companies (represented by the UK Major Hire Companies Group, MHCG) within the UK. The Major Contractors Group has announced that their members will only purchase tools whose vibration exposure have been tested and published on the HAVTEC database (MCG 2006).

There are numerous factors which influence the vibration exposure, such as tool construction, tool condition, attachment used, attachment condition, material of workpiece, direction of operation, operator posture, feed-force and grip force. These variables have been controlled as far as is practically possible for the OPERC tests whilst maintaining ecological validity. Rimell, Mansfield et al. (2006) presented data from rotary hammer drill measurements, where it was shown that the vibration exposure and/or drilling time varied significantly with drill bit diameter. At present, manufacturers' declared data is provided for a given tool irrespective of which attachment is used with that tool, and therefore may significantly underestimate the vibration exposure (an examination of the test code would reveal exactly how that tool was tested, for example, an impact drill tested to ISO 8662-6 (1995) is tested with an $8 \mathrm{~mm}$ diameter bit of minimum length $80 \mathrm{~mm}$ ). This paper compares the measured vibration magnitude data with the manufacturers' declared data for a wide range of different tool types and attachments including the drills previously analysed by Mansfield (2006a).

\section{Test methodology}

The data shown in this paper is taken from the measurements used to generate the data presented in the OPERC HAVTEC Database. The HAVTEC Database is a freely available database of over 700 tool/attachment summary measurements. In this paper the results of tests on a total of 105 tools (from a 
wide range of manufacturers) with a range of attachments are presented, resulting in a total of 656 sets of measurements. A number of specialist tools from the database have been intentionally excluded, as they are not within the scope of this paper.

The machine testing was carried out in accordance with ISO 5349-1 (2001). The measurements were conducted with two tri-axial ICP accelerometers (Piezotronics SEN021F) and two Larson-Davis IHVM 100 vibration meters, with the analogue output fed into a PC running bespoke data acquisition and analysis software complying with ISO 8041 (2005). The tri-axial acceleration was measured on both tool handles or on the part of the tool where it was supported by the operator's hand. The location of the accelerometers for the most common tool types are shown in Figure 1, which is in agreement with the suggested mounting locations given in the informative annex of ISO 5349-2 (2001). Both operators and testers wore the appropriate PPE (Personal Protective Equipment) for the individual test, comprising at least eye protection, hearing protection and safety boots.

For each handle, the total weighted r.m.s. vibration was calculated (using $\mathrm{W}_{\mathrm{h}}$ from ISO 5349-1 (2001)) and the greatest handle magnitude was then selected. For each combination of tool and attachment, three operators experienced in the use of the particular tool were each instructed to perform a minimum of five operations or five bursts of thirty seconds (ISO 20643 2005); if the total test time was less than 60 seconds, operators were instructed to continue with further repeats until 60 seconds of measurements were taken. The mean of the 15 or more measurements was recorded as the value for the given tool/attachment combination in the HAVTEC database. The mean value is reported in preference to any other statistical metric as this is mandated in ISO 5349. In this paper, these mean values are used for the analysis of each tool/attachment combination. Some tool/attachment combinations were tested on more than one occasion with different sets of operators and/or different attachments, and these have been included as separate measurements.

Table 2 details the various tool types, tasks, material types and attachment used in the test. The actual combination used depended on the tool being tested, for example, of the drills tested, only the drill-drivers 
were used as screwdrivers. All electrically powered tools operated from a $110 \mathrm{~V}$ a.c. power supply, with the exception of the one percussion drill which was operated from a $240 \mathrm{~V}$ a.c. supply. The concrete used for the majority of the testing comprised $40 \mathrm{~N} / \mathrm{mm}^{2}$ non-reinforced concrete, containing Derbyshire quartzite aggregate which had been allowed to cure for a minimum of 28 days (BS 206-1 2000). Other material used include $7 \mathrm{~N} / \mathrm{mm}^{2}$ concrete building blocks, red facing bricks, blue engineering bricks, steel and plastic pipes and wood.

\section{Results}

The results from the various tool measurements are shown in the following figures: Figure 2 for grinders; Figure 3 for breakers; Figure 4 for diamond core drills; Figure 5 for hammer drills; Figure 6 for battery powered drills; Figure 7 for saws and Figure 8 for sanders. Each of these graphs show the individual measured values (each symbol on the graph representing the mean of at least 15 repeats for a single combination of tool and attachment), the median of the measured values for the tool with $25^{\text {th }}$ and $75^{\text {th }}$ percentile, the manufacturer's declared value (note that for a few of the tools, no declared value was available) and the manufacturer's declared value after adjustment according to the CEN/TR 15350 (2006) using the multiplication factors shown in Table 1.

The measured vibration for the grinders is shown in Figure 2. The grinder measurements comprise standard angle grinders of different sizes (115 mm Ø [grinders 1 to 4 in Figure 2], $125 \mathrm{~mm} \varnothing$ [5-10], $150 \mathrm{~mm} \varnothing$ [11], and $230 \mathrm{~mm} \varnothing$ [12-18]), a wall chaser (with two parallel diamond discs) [19] and a rail cutter [20]. The standard angle grinders were tested with both abrasive and diamond cutting and grinding discs, the wall chaser was tested with two diamond discs and the rail cutter with an abrasive disc. It may be noted that, for each individual grinder, the results are neatly clustered together. The main exception is grinder 13 (a $230 \mathrm{~mm} \varnothing$ angle grinder), where the two lower measurements are for cutting concrete with abrasive and diamond blades respectively, and the higher magnitude measurement is for grinding concrete with an abrasive disc. There is no evidence to suggest that the large angle grinders have a significantly different magnitude of vibration to the small angle grinders (Independent-samples T-test, $p=0.223$ ). Figure 3 shows the results of the breaker tests, comprising electrical [breakers $1-9 \& 21-22$ in 
Figure 3], hydraulic [10-14] and pneumatic [15-20 \& 23-25] breakers using chisel or pointed attachments. It can be seen that for breaker 5 there is a wide spread of data, this is because that two high value measurements were tests where the breaker was used to tamp (pack) ballast under a railway sleeper using a specifically designed attachment, all other breaker measurements were for breaking $40 \mathrm{~N} / \mathrm{mm}^{2}$ concrete. An Independent-samples T-test shows that the electrical breakers (excluding the rail tamping test) were found to have a significantly higher magnitude vibration than the hydraulic breakers $(p<0.0001)$, and that the hydraulic breakers were significantly greater than the pneumatic breakers $(p<0.01)$. The results from the three diamond core drills are shown in Figure 4. Drills 1 and 2 were tested with a range of cutter diameters and in a range of materials as shown in Table 2 and drill 3 was tested with a range of cutter diameters in only $40 \mathrm{~N} / \mathrm{mm}^{2}$ concrete, which is reflected in Figure 4 where it can be seen that drills 1 and 2 have a greater spread of data. For drills 1 and 2, the greatest vibration was measured when drilling into $7 \mathrm{~N} / \mathrm{mm}^{2}$ concrete block, the next greatest for the red brick and the least for the $40 \mathrm{~N} / \mathrm{mm}^{2}$ concrete. The lowest two values for drill 2 was measured when the drill was mounted into a drilling rig which was held to the workpiece by use of a vacuum pump.

The results from the measurements of 23 rotary hammer drills [1-23], 1 percussion drill [24] and 1 pneumatic rock drill [25] are shown in Figure 5. It can be seen that the measured vibration from the rock drill (number 25) is lower than any of the other drills tested. The drills were tested with a range of bit sizes and makes, and in general the vibration increases as the drill bit size increases (see Rimell, Mansfield et al. (2006) for a detailed analysis of the effect of bit diameter and make/model on the recorded vibration exposure and drill performance). This is illustrated by the spread of values for each drill in Figure 5. For drill 15, for example, the lowest vibration measurement was made with the smallest diameter bit $(7 \mathrm{~mm})$, and the highest two were made with the largest two bits $(18 \mathrm{~mm}$ and $24 \mathrm{~mm} \emptyset)$. For the percussion drill (number 24) the lowest vibration measurement was made with a $7 \mathrm{~mm} \varnothing$ bit and the highest with a $13 \mathrm{~mm} \varnothing$ bit. Drills which can also be used for breaking or chipping (SDS with roto-stop) were also tested with the appropriate accessory (chisel or point) and the vibration magnitudes were, in general, towards the lower end of the range measured. For drill 20, the measured value whilst breaking was $4.6 \mathrm{~m} / \mathrm{s}^{2}$ below the lowest magnitude measured whilst drilling. The battery powered drills (Figure 6) showed the same general trend of vibration magnitude increasing with the size of the drill bit, this is 
particularly clear for drill 9 where the maximum vibration was measured with the 10 and $12 \mathrm{~mm} \varnothing$ drill bits and the minimum vibration was measured with a $8 \mathrm{~mm} \varnothing$ drill bit. With drill 11 the maximum vibration was with the largest drill bit $(10 \mathrm{~mm} \varnothing)$. The three measurements made with drill 13 were performed using different materials, the highest reading was for an $8 \mathrm{~mm} \emptyset$ hole into engineering blue brick, the central reading was for a $10 \mathrm{~mm} \emptyset$ hole into red facing brick, and the lowest reading was made drilling into softwood with a $12 \mathrm{~mm} \emptyset$ auger. The results from the measurements on saws is shown in Figure 7. The saws may be classified into three categories: circular saw [1], reciprocating saws [2-6] and stone saws [7-15]. The stone saws were either electrically powered, hydraulically powered or contained a petrol engine, and there is no observable link between the vibration and the power source. The circular saw was tested on $42 \mathrm{~mm}$ thick chipboard (such as may be found in a typical kitchen worktop). The reciprocating saws were tested on a range of materials resulting in a spread of measured vibration magnitudes, for example, the highest magnitude measurement made with saw 5 was on 22 mm thick chipboard, the second highest on $97 \mathrm{~mm}$ softwood batten and the remaining measurements made on thicker sections of wood and on steel pipe. The highest measurement made for saw 6 was on the thinnest section of softwood batten $(97 \mathrm{~mm})$. Finally, Figure 8 shows the results from the measurements of four sanders. Each of the sanders used a different mode of operation (sheet, drum, disc and belt) and was tested with at least two different grades of sandpaper, with only sander 4 showing a practical difference in vibration magnitude with respect to sandpaper grade, where the highest vibration resulted from the use of the finest sandpaper and the lowest vibration resulted from the use of the roughest sandpaper.

The results presented in this paper aim to be representative of the tool measured; however it should be stressed that the vibration emission varies with operator, task, tool, tool condition, accessory, accessory condition and workpiece material, therefore in practice, lower values are possible under ideal conditions and higher values are possible under worst-case conditions. The values presented here may be taken as typical values, but in certain circumstances (for example, the assessment of an individual employee's vibration exposure on a particular job) a further risk assessment exercise would need to be performed. 


\section{Discussion}

The vibration exposure measured is within a similar range to other published data (Hewitt 2004, Hewitt, Smeatham 2005, NIWL) given that the permissible tolerances stated by ISO 8041 (2005) are $\pm 4 \%$ for r.m.s. measurements, possibly rising to $\pm 10 \%$ at the extremes of the frequency range due to the wide tolerance of the weighting filters (Darlington, Tyler 2004). In practice, variations between different measurements of the same tool/attachment made using a range of measurement equipment have been found to be as high as 30\% (Darlington, Tyler 2004) due to the differences between the vibration meters and the small differences between accelerometer positioning (when the same tool was repeatedly retested with re-mounting of the accelerometers). The main difference between the data presented in this paper and data previously published, is that this data comprises a range of tools, each tested with a range of typical attachments on a range of material types, thus providing a representative range of vibration emission for each tool. Rimell, Mansfield et al. (2006) have shown that vibration emission varies significantly with drill bit diameter for hammer drills and Hussain (2005) has shown that vibration increases whilst productivity (i.e. drilling time) decreases as the tool wears out. Mansfield (2006a) analysed a subset of the data presented here, and noted that in the case of hammer drills, for tools with a declared value of below $10 \mathrm{~m} / \mathrm{s}^{2}$, the measured exposure value was generally greater than the declared emission value, whereas for drills with a declared value of above $10 \mathrm{~m} / \mathrm{s}^{2}$ the measured exposure value was generally similar to the declared emission values. Thus, if the multiplication factors were applied to the manufacturers' declared data, those tools reporting a higher (but more representative) value would be penalised.

In addition to the measured vibration exposure, Figures 2 to 8 show the median value for the tool (with the $25^{\text {th }}$ and $75^{\text {th }}$ percentile values shown as error bars), the manufacturers' declared vibration emission and the declared emission with multiplication factor defined in CEN/TR 15350 (2006). It can be seen that for some tools the declared value is a reasonable approximation of the measured vibration exposure for the conditions tested here (for example, grinder 15 and hammer drill 5). However, for other tools, such as breaker 11, the measured values are considerably less than the published emission value, resulting in an adjusted emission value that is over three times both the median and mean measured vibration 
emission values for that tool. The correlation between the measured values (both the mean and median for all measurements of a given tool) and the declared values (both as presented by the manufacturers and adjusted) was tested for all 105 tools using a Pearson correlation test. It was found that all of the correlations were highly significant $(p<0.01)$, with correlation values of between 0.665 and 0.694 , suggesting that in general the ranking of the declared values are a reasonable first approximation to the ranking of the measured data.

The manufacturer's declared value for the grinders (as shown in Figure 2) was lower than the measured $25^{\text {th }}$ percentile value for all but three grinders (grinders 13,15 and 16 ). The large $75^{\text {th }}$ percentile value for grinder 13 is due to the high magnitude of exposure measured when grinding concrete with an abrasive disc. For a number of the breakers (for example, breakers 3, 8, 12, 15, 17, 22 and 24), the declared value is a good approximation of the measured emission, whereas for other breakers (for example, breakers 4 , 10, 13 and 20), the adjusted value can be seen to be a good approximation, and for some breakers neither the declared or adjusted values are a good approximation (for example, breaker 11). For each of the diamond core drills tested (used with a range of different size cutters on concrete, red and blue brick), the declared value is at the lower end of the measured vibration emission; however, for two of the drills tested (No 1 and No 3 ) the declared value is within the $25^{\text {th }}$ percentile. The declared value is a good estimation of the vibration exposure for drill 2 when the drill is mounted into a drilling rig, but is lower than the measured median value when the drill is hand held. The tool categories containing the most tests (and possibly the most widely used in the construction industry) are the drill categories (divided into two groups: hammer and battery powered). In general, for the hammer drills, the declared value underestimates the measured vibration emission and the adjusted declared value overestimates the measured emission value. For the reciprocating saws (Saws 2 to 6 in Figure 7), the declared values underestimate the measured exposure; however, for the circular saw and the petrol stone saws for which data was available, the declared values are reasonable approximations to the measured vibration emission. It may be observed that for the sanders, Figure 8, the declared emission values are very good estimates of the measured vibration emission. For Sanders 1 to 3, this is due the fact that the declared value is based on the measured data presented in this paper; however, sander 4's declared data is not based on these tests and is also an excellent estimation of the measured vibration exposure. The findings presented here are 
broadly in agreement with those presented by Hewitt and Smeatham (2006), although a greater variety and number of tools have been presented here. Cumulative histogram plots are presented for each tool with more than eight measurements and are shown in Figures 9 to 11. These plots show the percentage of measurements that are below a particular measured value, and also show the percentage of measurements below the declared and adjusted values (declared values are denoted by a square and adjusted values by a triangle). Figure 9 shows the cumulative histogram plots for eight of the hammer drills. For hammer drill 1 , all of the measured data is below the declared and adjusted values, for hammer drill 2 , the measured values lie between the declared and adjusted values and for hammer drill 10, the adjusted value lies in the centre of the measurement range, indicating that it is an excellent approximation to the measured value. Figure 10 shows the cumulative histograms for six hammer drills and two diamond core drills and Figure 11 shows the cumulative histograms for five grinders, one battery drill and two saws. This method of representing the data clearly shows the effectiveness of the declared and adjusted values.

In order to compare across the different tool types, the percentage error in the estimation of the vibration exposure from the declared values data was calculated (for data which declared emission values were available). The results are shown in Figure 12, with open symbols representing manufacturers declared data and solid symbols representing declared data adjusted to CEN/TR 15350 (2005). Different shaped symbols are used to represent the different tool categories. The mean value for each tool type was calculated and is shown in Table 3. It can be seen from Figure 12 and Table 3 that, in general, the manufacturers' declared data underestimates the vibration exposure, whereas the adjusted declared values overestimate the vibration exposure. For all tool types other than the grinders, the mean error is lower when using the manufacturers' declared data rather than that obtained by using the correction factors in CEN/TR 15350 (2005). However, considering the inherent uncertainty in vibration emission of tools it is recommended that if a user is required to perform a risk assessment using manufacturers' declared values, that the correction factors are used in order to err on the side of caution with respect to health risk. Given the differences between actual measured vibration exposure values and declared/adjusted values, the ideal scenario for risk assessment is to measure the vibration emission of the actual tool in question performing the appropriate task on the appropriate material with the appropriate accessory (bearing in mind that the measurement is only truly representative of the tool used under that set of conditions). When it is not 
possible or practical to measure the tool in question, one could obtain the most representative vibration exposure value from a database of ISO 5349-1 (2001) measured data which includes tools measured with a range of accessories on different materials, such as the OPERC HAVTEC database.

Each of the 656 individual data points in Figures 2 to 8 comprises the mean value of at least fifteen measurements made with three operators performing at least five repeats each. The coefficient of variation of each of those data points is defined as the ratio of the standard deviation to the mean (expressed here as a percentage) and is an indication of the variation within the measurement process itself - a low value indicating that the measurement is representative of the tool under those test conditions. Factors that may give variability in the measurement process include operator stature, mass, posture, grip force and feed force. The coefficient of variation for each individual measurement is shown in Figure 13, with the means calculated for each category and also for all categories combined as shown in Table 4. From Figure 13, it can be seen that the grinder, diamond core drill and saw measurements exhibit the greatest variation; however, the coefficient of variation is less than $15 \%$ for 496 of the 656 measurements presented here, and the mean value of all tools is $12 \%$. These values compare favourably with those presented previously: Hewitt (2004) measured a number of power tools found in the woodworking industry and presented data with a coefficient of variability of $40 \%$ for saws and $43 \%$ for sanders, and Persson (2005) presented data for angle grinders grinding steel: $125 \mathrm{~mm}$ angle grinders with a coefficient of variability of $35 \%$ and $230 \mathrm{~mm}$ angle grinders with a coefficient of variability of $20-25 \%$. Stayner (1996) discusses in detail the vibration emission of angle grinders, including an analysis of the main sources of variance in the measured vibration, with the main sources of variance being the design of the machine, the balance of the grinder wheel and the width of the workpiece.

\section{Conclusions}

This paper has presented a set of 656 measurements of vibration exposure (to ISO 5349-1 (2005)) of 105 power tools and attachments typically found in the construction industry. The data presented here is freely available from the OPERC HAVTEC database, and includes each tool measured with a typical range of attachments in order to provide realistic vibration exposure data. The database has been 
sponsored by major tool manufacturers, industry groups and hire companies from within the UK, and represents a significant collaboration between different sectors of the construction industry and academia.

The measured data were compared with manufacturers' published vibration emission data with and without the multiplication factors presented in CEN/TR 15350 (2006). It was found that for some tools the manufacturers' declared emission data was a good estimation of the measured vibration exposure, whilst for other tools the manufacturers' declared emission data with the multiplication factor was a good estimate, and for others neither method resulted in a good estimate. In general, the manufacturers' declared emission data tended to under estimate the measured exposure and the adjusted emission data (after application of multiplication factors) tended to over estimate the measured vibration exposure. It was found that there was a statistically significant correlation $(p<0.01)$ between mean and median of the measured exposure values with the declared and adjusted emission values (with a Pearson correlation coefficient of between 0.665 and 0.694 ), indicating that the declared values provide a reasonable first approximation of the measured vibration exposure. From the analysis of the estimation error, it is suggested that the adjusted value be used for grinders and the manufacturers' declared value be used for the other tool types tested here. In terms of tool types, it was found that the estimation error for the declared data was: Sanders $(-3.7 \%)$, grinders - after multiplication factors $(-8.3 \%)$, battery powered drills $(-8.8 \%)$, breakers $(-12.5 \%)$, saws $(-18.2 \%)$, hammer drills $(-18.6 \%)$ and diamond core drills $(-58.5 \%)$.

The ideal scenario for risk assessment is to measure the vibration emission of the actual tool in question performing the appropriate task on the appropriate material with the appropriate accessory. When it is not possible or practical to measure the tool in question, one could obtain the most representative vibration exposure value from a database of ISO 5349-1 (2001) measured data which includes tools measured with a range of accessories on different materials, or otherwise use the manufacturer's declared data with the multiplying factor where appropriate. 


\section{References}

ANSI S2.70, 2006. (Revision of ANSI S3.34-1986) Guide for the Measurement and Evaluation of Human Exposure to Vibration Transmitted to the Hand. American National Standards Institute (ANSI).

BS 206-1, 2000. Concrete - Part 1: Specification, performance, production and conformity. British Standards Institute (BSI).

CEN/TR 15350, 2006. Mechanical vibration - Guideline for the assessment of exposure to handtransmitted vibration using available information including that provided by manufacturers of machinery. European Committee for Standardization (CEN).

DARLINGTON, P. and TYLER, R., 2004. Measurement uncertainty in human exposure to vibration, 2004, Presented at the 39th UK Group Meeting on Human Response to Vibration.

DONG, R.G., RAKHEJA, S., SCHOPPER, A.W., HAN, B. and SMUTZ, W.R., 2001. Hand-transmitted vibration and biodynamic response of the human hand-arm: A critical review. Critical Reviews in Engineering, 29(4), pp. 393-439.

EDWARDS, D.J. and HOLT, G.D., 2005. Exposure to hand-arm vibration: Implications of new statutory requirements. Building Research and Information, 33(3), pp. 257-266.

EN 60745, 2003. Hand-held motor-operated electric tools - Safety - Part 1: General requirements. European Committee for Electrotechnical Standardization (CENELEC).

EUROPEAN COMMISSION, 2002. Directive 2002/44/EC of the European Parliament and of the Council of 25 June 2002 on the minimum health and safety requirements regarding exposure of workers to the risks arising from physical agents. Official Journal of the European Communities L177, pp. 13-19. EUROPEAN COMMISSION, 1998. Directive 98/37/EC of the European Parliament and of the Council of 22 June 1998 on the approximation of the laws of the member states relating to machinery. Official Journal of the European Communities L207, pp. 1-46. 
EUROPEAN COMMISSION, 2006. Directive 2006/42/EC of the European Parliament and of the

Council of 17 May 2006 on machinery, and amending Directive 95/16/EC (recast). Official Journal of the European Communities L157, pp. 24-86.

HEWITT, S., 2004. Assessment of HAV risks in woodworking, Presented at the 39th UK Group Meeting on Human Response to Vibration.

HEWITT, S. and NELSON, C., 2005. Assessment of hand-arm vibration exposure, Proceedings of the Institute of Acoustics, 27(3).

HEWITT, S. and SMEATHAM, D., 2005. Manufacturer's declared vibration emission and risk assessment, Presented at the 40th UK Group Meeting on Human Response to Vibration.

HEWITT, S. and SMEATHAM, D., 2006. Comparison of vibration emission data declared for powered hand-tools with vibration in use: Review of findings from 1998 to 2000: Final report. HSL (Health and Safety Laboratory) Report HSL/2006/91.

HSE, 2003. Improving health and safety in construction: Phase 2 - Depth and breadth, Volume 4. Hand Arm Vibration Syndrome - Underlying causes and risk control in the construction industry. HSE (Health and Safety Executive) Research Report 114, HSE Books, ISBN 0-7176-2219-3.

HUSSAIN, W., 2005. Construction Industry Initiative to reduce HAVS health risk, Presented at the 40th UK Group Meeting on Human Response to Vibration.

ISO 20643, 2005. Mechanical vibration — Hand-held and hand-guided machinery — Principles for evaluation of vibration emission. International Organization for Standardization (ISO).

ISO 5349-1, 2001. Mechanical vibration - Measurement and evaluation of human exposure to handtransmitted vibration - Part 1: General Requirements. International Organization for Standardization (ISO).

ISO 5349-2, 2002. Mechanical vibration - Measurement and evaluation of human exposure to handtransmitted vibration - Part 2: Practical guidance for measurement at the workplace. International Organization for Standardization (ISO). 
ISO 8041, 2005. Human response to vibration - Measuring instrumentation. International Organization for Standardization (ISO).

ISO 8662-1, 1988. Hand-held portable power tools — Measurement of vibrations at the handle — Part 1: General. International Organization for Standardization (ISO).

ISO 8662-4, 1994. Hand-held portable power tools - Measurement of vibrations at the handle — Part 4: Grinding machines. International Organization for Standardization (ISO).

ISO 8662-6, 1995. Hand-held portable power tools — Measurement of vibrations at the handle — Part 6: Impact drills. International Organization for Standardization (ISO).

MANSFIELD, N.J., 2005. Human response to vibration. CRC Press, ISBN 0-415-28239-X.

MANSFIELD, N.J., 2006. Filling the gap between manufacturers' declared values and hand-arm vibration emission under real working conditions, Proceedings of the Institute of Acoustics, 28(3).

MANSFIELD, N.J., 2006a. Variation in the vibration emission of rotary hammer drills under simulated work-site conditions, Presented at the 1st American Conference on Human Vibration, NIOSH, USA.

MCG, 2006. Major contractors set deadline for independent vibration testing, Main Contractors Group Press Release, http://www.mcg.org.uk/pdf/HAVS\%20PR\%20\%20MCG\%20\%20\%20Sep\%2006.pdf, 24 August 2006.

NIWL, National Institute for Working Life (Sweden), http://umetech.niwl.se/eng/.

OPERC, Hand-Arm Vibration Test Centre (HAVTEC), http://www.operc.com/pages/havtecwelcome.asp. PERSSON, M., 2005. Vibration measurement methods for grinders, a round robin evaluation, Presented at the 40th UK Group Meeting on Human Response to Vibration.

REYNOLDS, D.D., 2006. New ANSI S3.34 (2.70-2006) - Guide for the measurement and evaluation of human exposure to vibration transmitted to the hand, Presented at the 41st UK Group Meeting on Human Response to Vibration. 
RIMELL, A., MANSFIELD, N.J. and EDWARDS, D.J., 2006. The influence of drill-bit on the measured vibration exposure of hammer drills, Presented at the 41st UK Group Meeting on Human Response to Vibration.

STAYNER, R.M., 1996. Grinder characteristics and their effects on hand-arm vibration. HSE (Health and Safety Executive) Contract Research Report No 115/1996, HSE Books, ISBN 0-7176-1265-1.

WASSERMAN, D.E., 1985. Raynaud phenomenon as it relates to hand-tool vibration in the workplace. American Industrial Hygiene Association Journal, 46(12), pp. B10.

\section{Acknowledgements}

The images in Figure 1 are used with the permission of Makita UK. 


\begin{tabular}{|lc||lc|}
\hline Tool & $\begin{array}{c}\text { Multiplication } \\
\text { factor }\end{array}$ & Tool & $\begin{array}{c}\text { Multiplication } \\
\text { factor }\end{array}$ \\
\hline Angle grinder (grinding) & 1.5 & Drill (screwing \& diamond core) & 1.0 \\
\hline Angle grinder (polishing) & 1.0 & Drill (percussion) & 1.5 \\
\hline Breaker (electrical) & 1.5 & Drill (hammer) & 2.0 \\
\hline Breaker (pneumatic) & 2.0 & Reciprocating saw & 2.0 \\
\hline Circular saw & 1.5 & Sander & 1.5 \\
\hline
\end{tabular}

Table 1: Multiplication factors given in CEN/TR 15350 (2006) for the tools presented in this paper, used for the estimation of vibration exposure in the workplace (such as that determined by an ISO 5349 (2001) compliant test) from declared values determined in the laboratory (such as that determined by an ISO 8662-1 (1988) compliant test). CEN/TR 15350 (2006) also provides multiplication factors for many other tools that are not considered here. Note that for the Angle Grinder in polishing mode, CEN/TR 15350 states that "Value in real use likely to be lower", a value of 1.0 has been used here as the angle grinder was polishing a concrete paving slab with a diamond polishing disk which would create higher vibration magnitudes than a soft polishing mop on a smooth surface. 


\begin{tabular}{|c|c|c|c|}
\hline $\begin{array}{l}\text { Tool } \\
\text { (Number tested : } \\
\text { combinations tested) }\end{array}$ & Operation & Material & Attachment \\
\hline Grinder (20:95) & $\begin{array}{l}\text { Cutting, } \\
\text { grinding, } \\
\text { polishing }\end{array}$ & $\begin{array}{l}40 \mathrm{~N} / \mathrm{mm}^{2} \text { concrete, steel, } \\
\text { stainless steel, mortar, red } \\
\text { brick, blue brick, mainline rail }\end{array}$ & $\begin{array}{l}\text { Diamond disc, abrasive } \\
\text { disc }\end{array}$ \\
\hline Breaker $(25: 38)$ & $\begin{array}{l}\text { Breaking, } \\
\text { tamping rail } \\
\text { ballast }\end{array}$ & $\begin{array}{l}40 \mathrm{~N} / \mathrm{mm}^{2} \text { concrete, railway } \\
\text { ballast }\end{array}$ & Point, chisel, tamper \\
\hline $\begin{array}{l}\text { Diamond core drill } \\
(3: 32)\end{array}$ & Drilling & $\begin{array}{l}40 \mathrm{~N} / \mathrm{mm}^{2} \text { concrete, } 7 \mathrm{~N} / \mathrm{mm}^{2} \\
\text { concrete block, red brick }\end{array}$ & $\begin{array}{l}\text { Diamond core bits } \\
(25-430 \mathrm{~mm} \varnothing)\end{array}$ \\
\hline $\begin{array}{l}\text { Hammer drill }(25: 359) \\
\text { and Battery powered } \\
\text { drill }(13: 64)\end{array}$ & $\begin{array}{l}\text { Drilling, } \\
\text { breaking, } \\
\text { screwing }\end{array}$ & $\begin{array}{l}40 \mathrm{~N} / \mathrm{mm}^{2} \text { concrete, red brick, } \\
\text { blue brick, softwood }\end{array}$ & $\begin{array}{l}\text { Drill bits (4 - } 44 \mathrm{~mm} \emptyset) \text {, } \\
\text { point, chisel }\end{array}$ \\
\hline Sander (4: 9) & Sanding & Softwood & $\begin{array}{l}\text { Abrasive paper } \\
\text { ( } 5 \text { grades })\end{array}$ \\
\hline Saw (15: 59) & Cutting & $\begin{array}{l}\text { Softwood, plywood, } \\
\text { chipboard, steel pipe, plastic } \\
\text { pipe, mortar, } 40 \mathrm{~N} / \mathrm{mm}^{2} \\
\text { concrete, } 7 \mathrm{~N} / \mathrm{mm}^{2} \text { concrete } \\
\text { block, red brick, blue brick }\end{array}$ & $\begin{array}{l}\text { wood cutting blade, } \\
\text { metal cutting blade, } \\
\text { plastic cutting blade, } \\
\text { diamond disc, abrasive } \\
\text { disc }\end{array}$ \\
\hline
\end{tabular}

Table 2: Summary of tools tested, with operation performed, material processed and accessory used. The actual combination of tool, operation, material and accessory depended on the tool being measured and not every combination shown in the table was tested. Column 1 also shows the number of different models of tool tested along with the number of combinations of tool, operation, material and attachment tested. 


\begin{tabular}{|c|c|c|c|c|c|c|c|c|}
\hline & 离 & 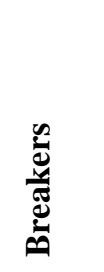 & 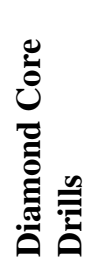 & 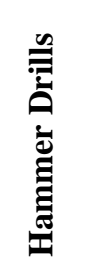 & 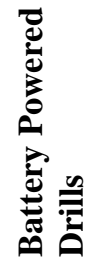 & $\frac{n}{\tilde{E}}$ & 糹 & 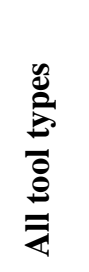 \\
\hline $\begin{array}{l}\text { Declared } \\
\text { (Mean of \% error) }\end{array}$ & -36.6 & -12.5 & -58.5 & -18.6 & -8.8 & -3.7 & -18.2 & -19.3 \\
\hline $\begin{array}{l}\text { Adjusted to } \\
\text { CEN/TR } 15350 \\
\text { (Mean of \% error) }\end{array}$ & -8.3 & 57.4 & -58.5 & 62.9 & 52.4 & 44.5 & 44.1 & 41.6 \\
\hline
\end{tabular}

Table 3: Mean of the percentage error presented in Figure 12 as a function of tool type and for all tools combined. 


\begin{tabular}{|lc||lc|}
\hline \multicolumn{1}{|c||}{ Tool type } & $\begin{array}{c}\text { Mean coefficient of } \\
\text { variation }(\%)\end{array}$ & \multicolumn{1}{|c|}{ Tool type } & $\begin{array}{c}\text { Mean coefficient of } \\
\text { variation (\%) }\end{array}$ \\
\hline Grinders & 16.0 & Battery powered drills & 11.4 \\
\hline Breakers & 10.8 & Sanders & 13.5 \\
\hline Diamond core drills & 20.6 & Saws & 12.2 \\
\hline Hammer drills & 10.4 & All tools & 12.0 \\
\hline
\end{tabular}

Table 4: Mean coefficient of variation presented in Figure 13 as a function of tool type and for all tools combined. 


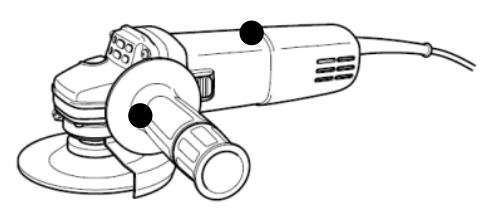

Small angle grinder

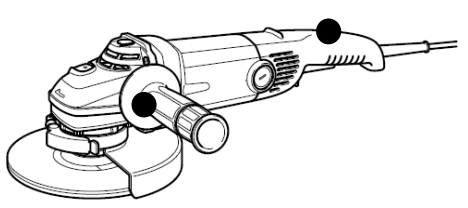

Large angle grinder

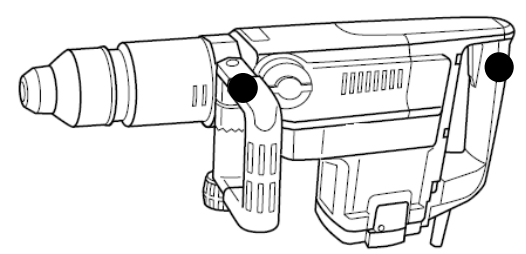

Breaker or large drill

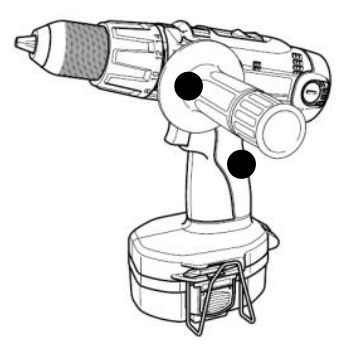

Small drill

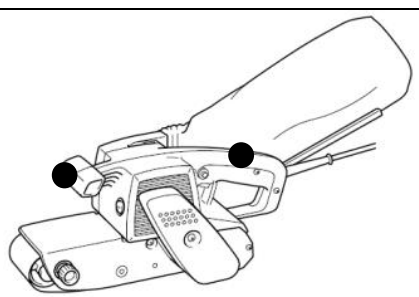

Belt sander

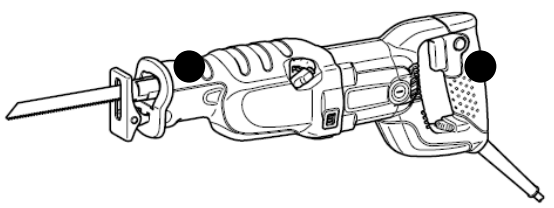

Reciprocating saw

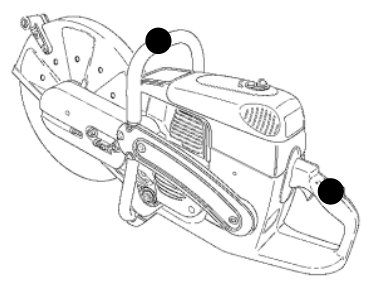

Stone saw

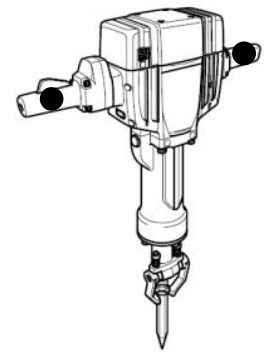

Breaker

Figure 1: Tri-axial accelerometer mounting locations for the most common tool types (all of the tools tested were held with two hands). 


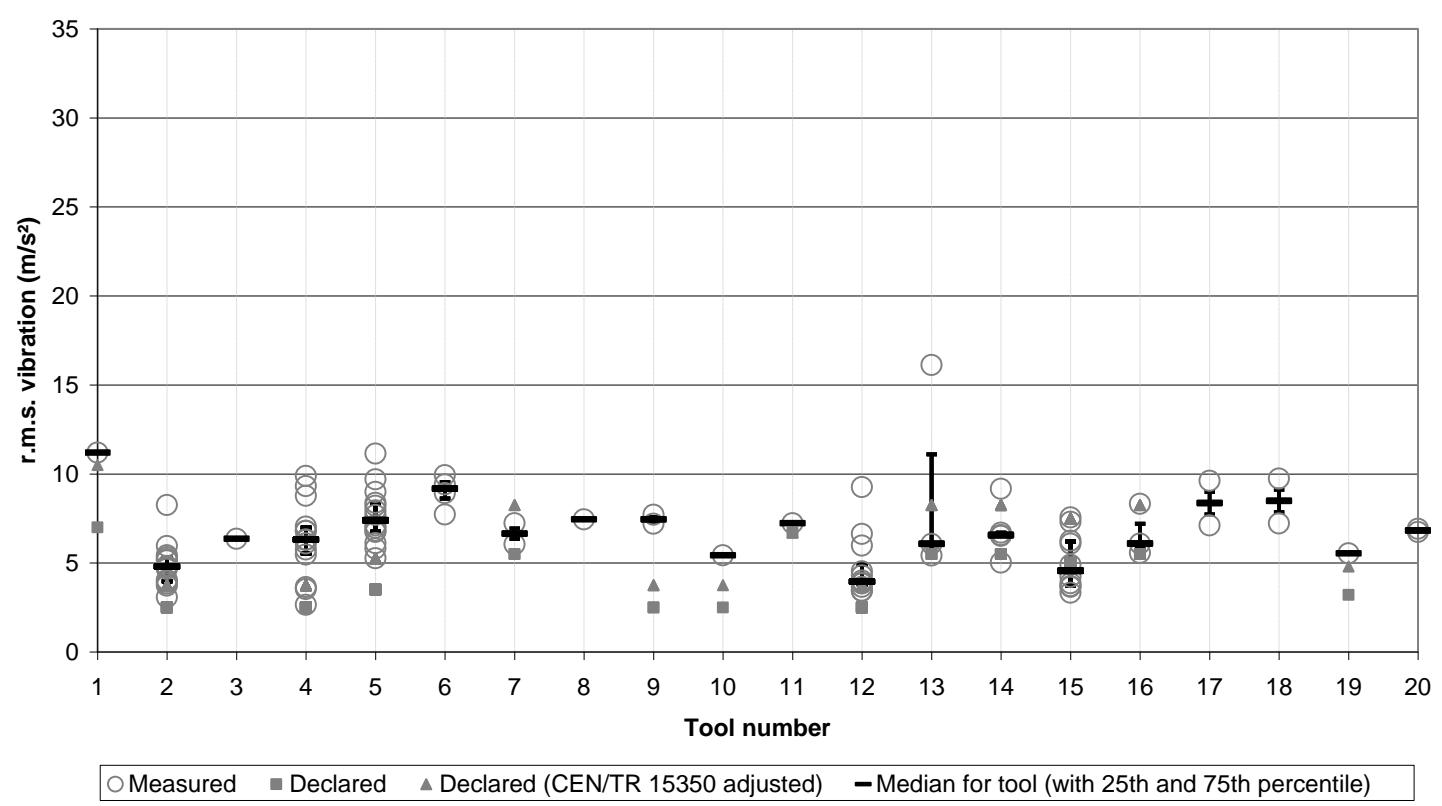

Figure 2: Measured vibration exposure (ISO 5349-1 2001), manufacturers' declared vibration exposure and adjusted declared vibration exposure (CEN/TR 15350 2006) for 20 grinders (115 mm $\emptyset$ angle grinder [1-4], $125 \mathrm{~mm} \emptyset$ angle grinder [5-10], $150 \mathrm{~mm} \emptyset$ angle grinder [11], $230 \mathrm{~mm} \emptyset$ angle grinder [12-18], wall chaser [19] and rail cutter [20]). Note that for each grinder multiple values may indicate repeat measurements or measurements using different types of cutting disk. Also note that declared values below $2.5 \mathrm{~m} / \mathrm{s}^{2}$ have been rounded up to $2.5 \mathrm{~m} / \mathrm{s}^{2}$ as recommended in CEN/TR 15350 (2006). 


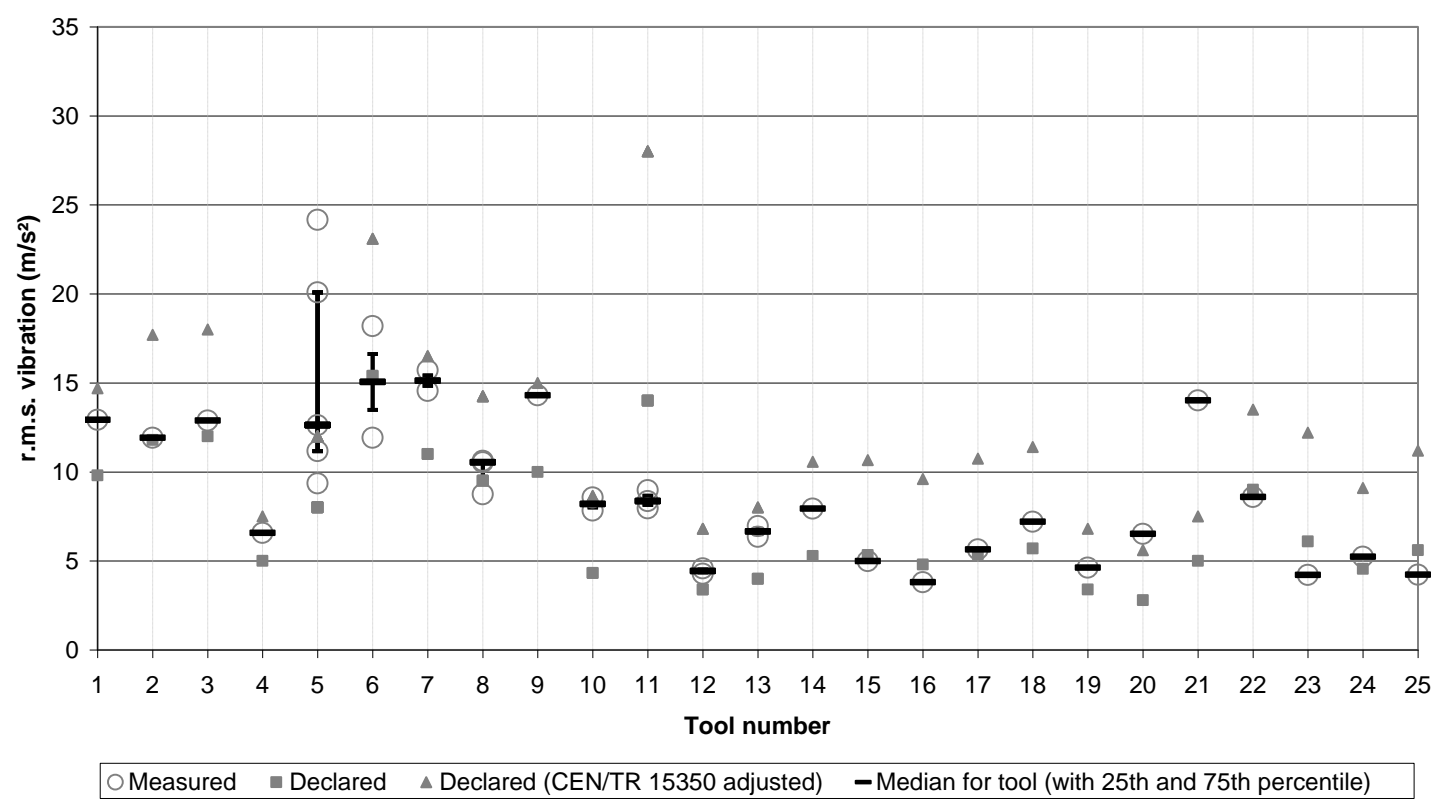

Figure 3: Measured vibration exposure (ISO 5349-1 2001), manufacturers' declared vibration exposure and adjusted declared vibration exposure (CEN/TR 15350 2006) for 25 breakers (electrical [1-9 \& 21-22], hydraulic [10-14] and pneumatic [15-20 \& 23-25]). Note that for each breaker multiple values may indicate repeat measurements or measurements using different types of inserted tool. 
Diamond core drills

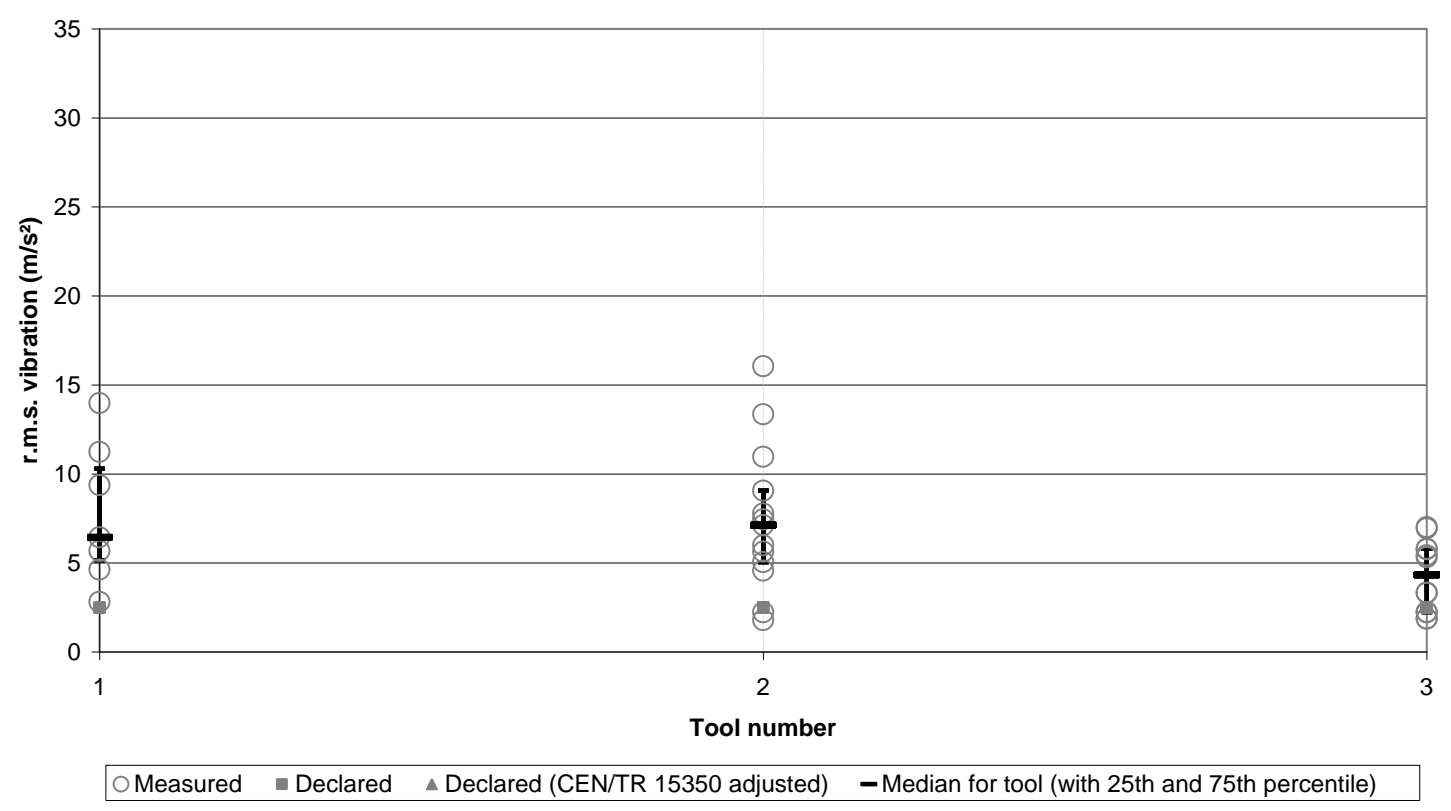

Figure 4: Measured vibration exposure (ISO 5349-1 2001), manufacturers' declared vibration exposure and adjusted declared vibration exposure (CEN/TR 15350 2006) for 3 diamond core drills. Note that for each drill multiple values may indicate repeat measurements or measurements using different sizes of core. 


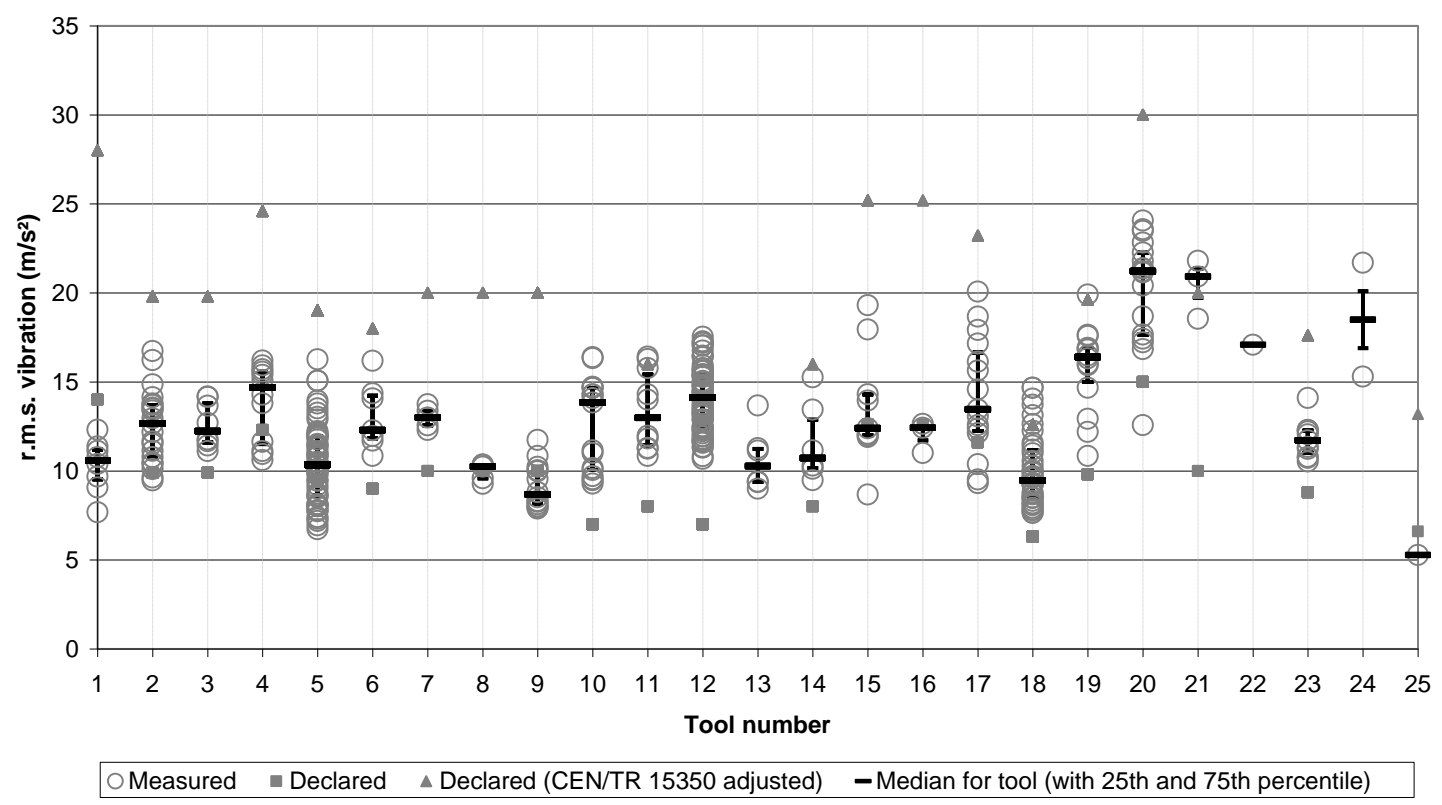

Figure 5: Measured vibration exposure (ISO 5349-1 2001), manufacturers' declared vibration exposure and adjusted declared vibration exposure (CEN/TR 15350 2006) for 25 hammer drills (electrical [1-24] and pneumatic [25]). Note that for each drill multiple values may indicate repeat measurements or measurements using different types or sizes of bit. 


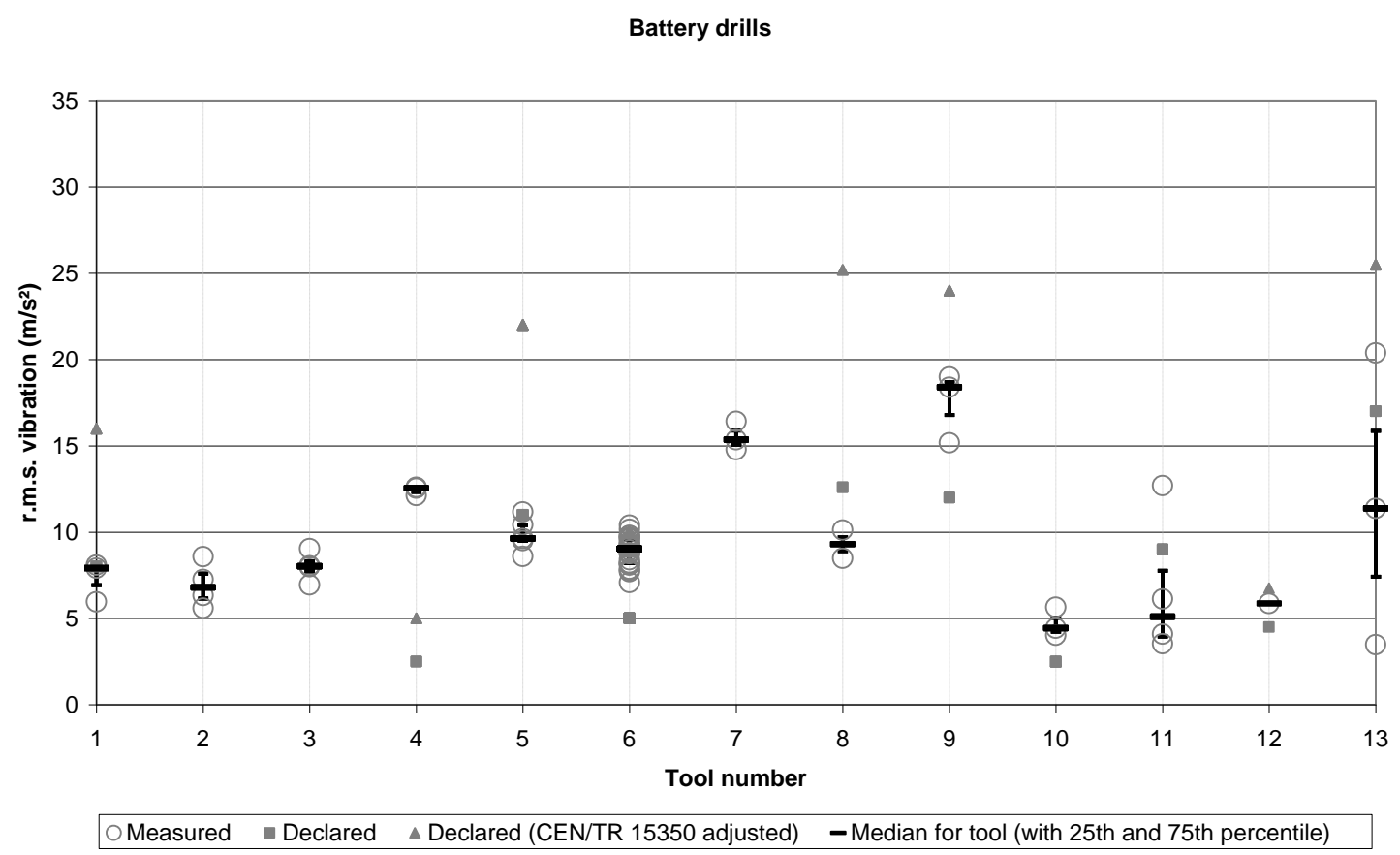

Figure 6: Measured vibration exposure (ISO 5349-1 2001), manufacturers' declared vibration exposure and adjusted declared vibration exposure (CEN/TR 15350 2006) for 13 battery powered drills (hammer drill [1-9], drill-driver screwing [10-11] and percussion drill [12-13]. Note that for each drill multiple values may indicate repeat measurements or measurements using different types or sizes of bit. 


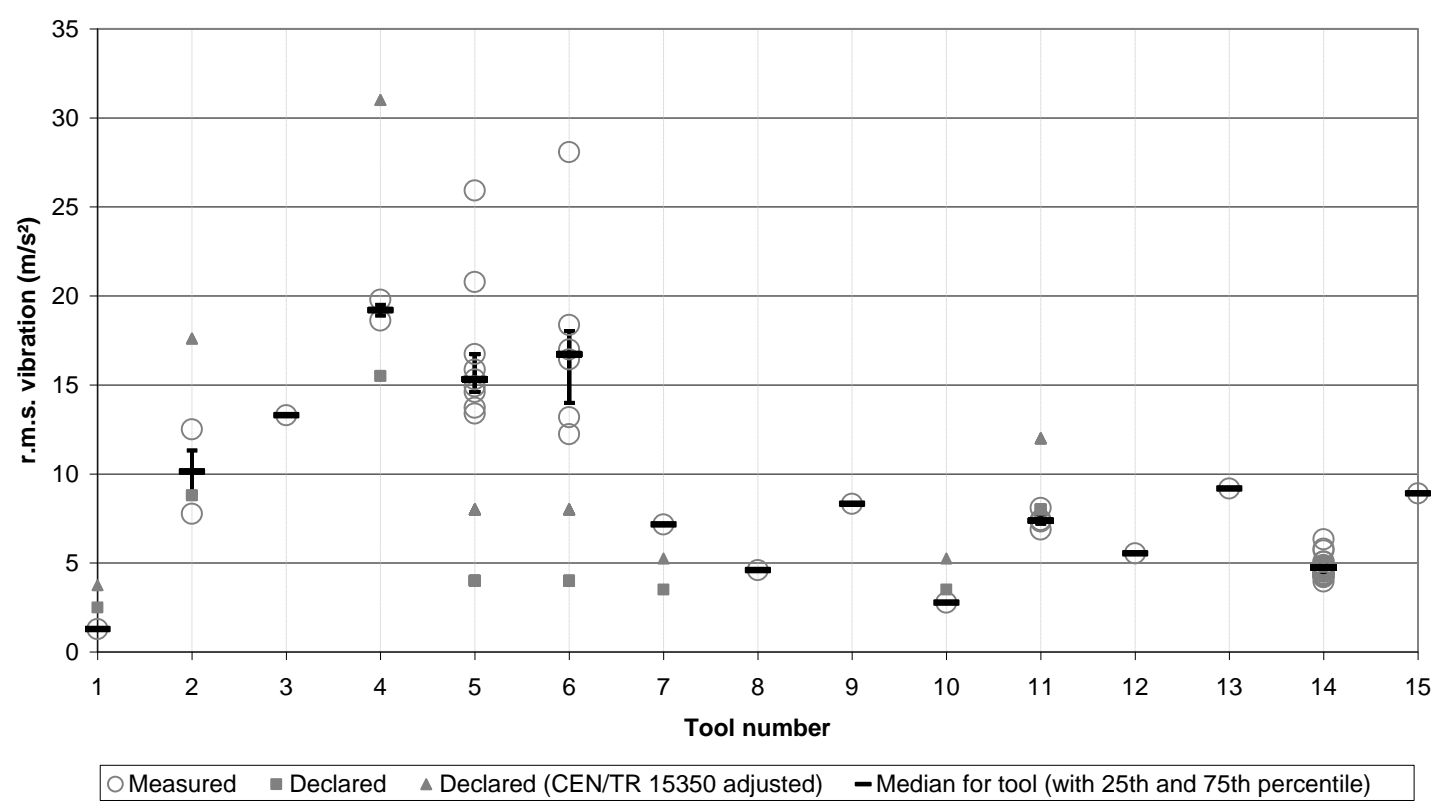

Figure 7: Measured vibration exposure (ISO 5349-1 2001), manufacturers' declared vibration exposure and adjusted declared vibration exposure (CEN/TR 15350 2006) for 15 saws (electrical circular saw [1], electrical reciprocating saw [2-6], electrical stone saw [7], hydraulic stone saw [8-9] and petrol stone saw [10-15]). Note that for each saw multiple values may indicate repeat measurements or measurements using different types of blade. 
Sanders

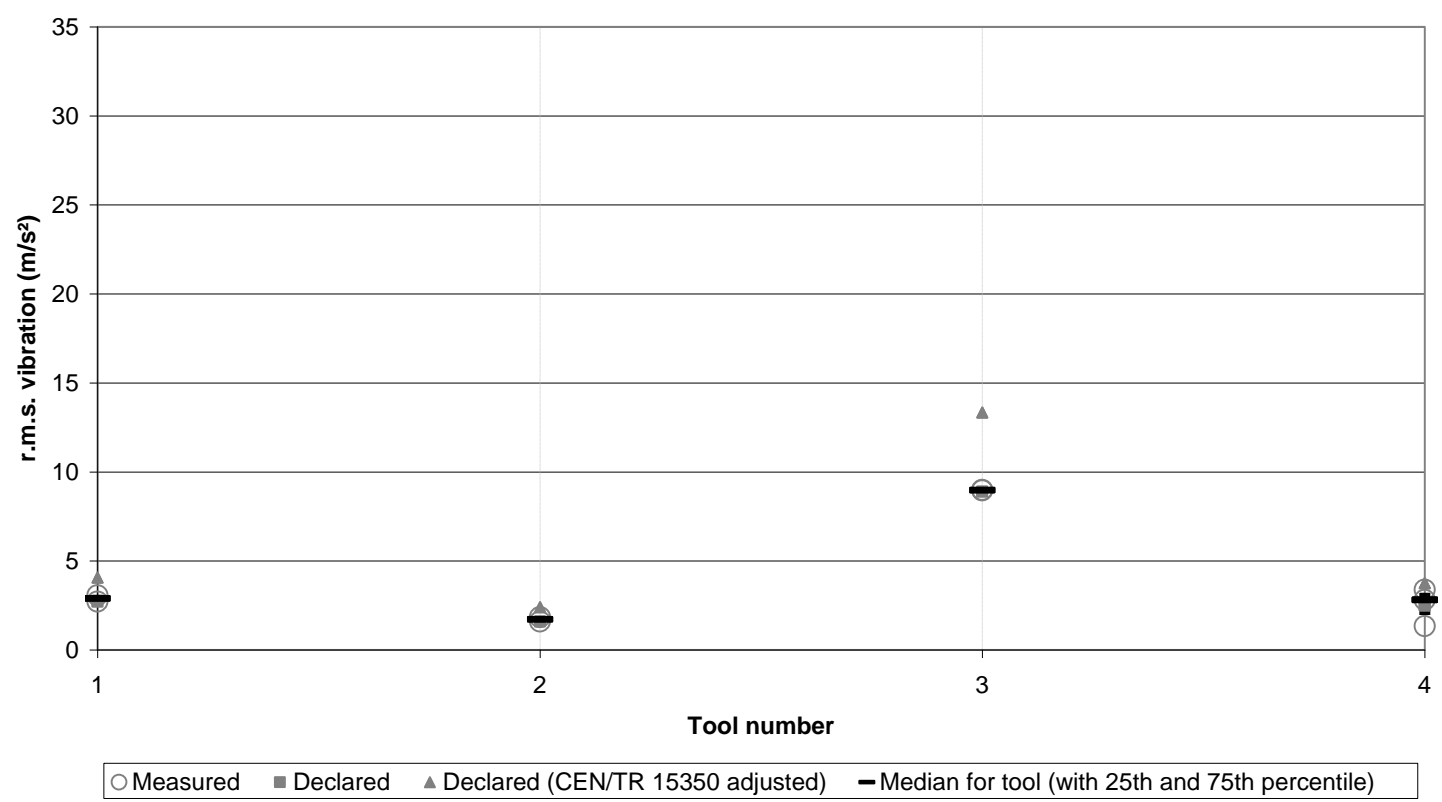

Figure 8: Measured vibration exposure (ISO 5349-1 2001), manufacturers' declared vibration exposure and adjusted declared vibration exposure (CEN/TR 15350 2006) for 4 sanders (sheet [1], drum [2], disc [3] and belt [4]). Note that for each sander multiple values may indicate repeat measurements or measurements using different grades of sandpaper. Also note that the declared values for sanders 1 to 3 are based on the ISO 5349 measurements presented here, and have therefore not been rounded up to $2.5 \mathrm{~m} / \mathrm{s}^{2}$ as recommended in CEN/TR 15350 (2006). 


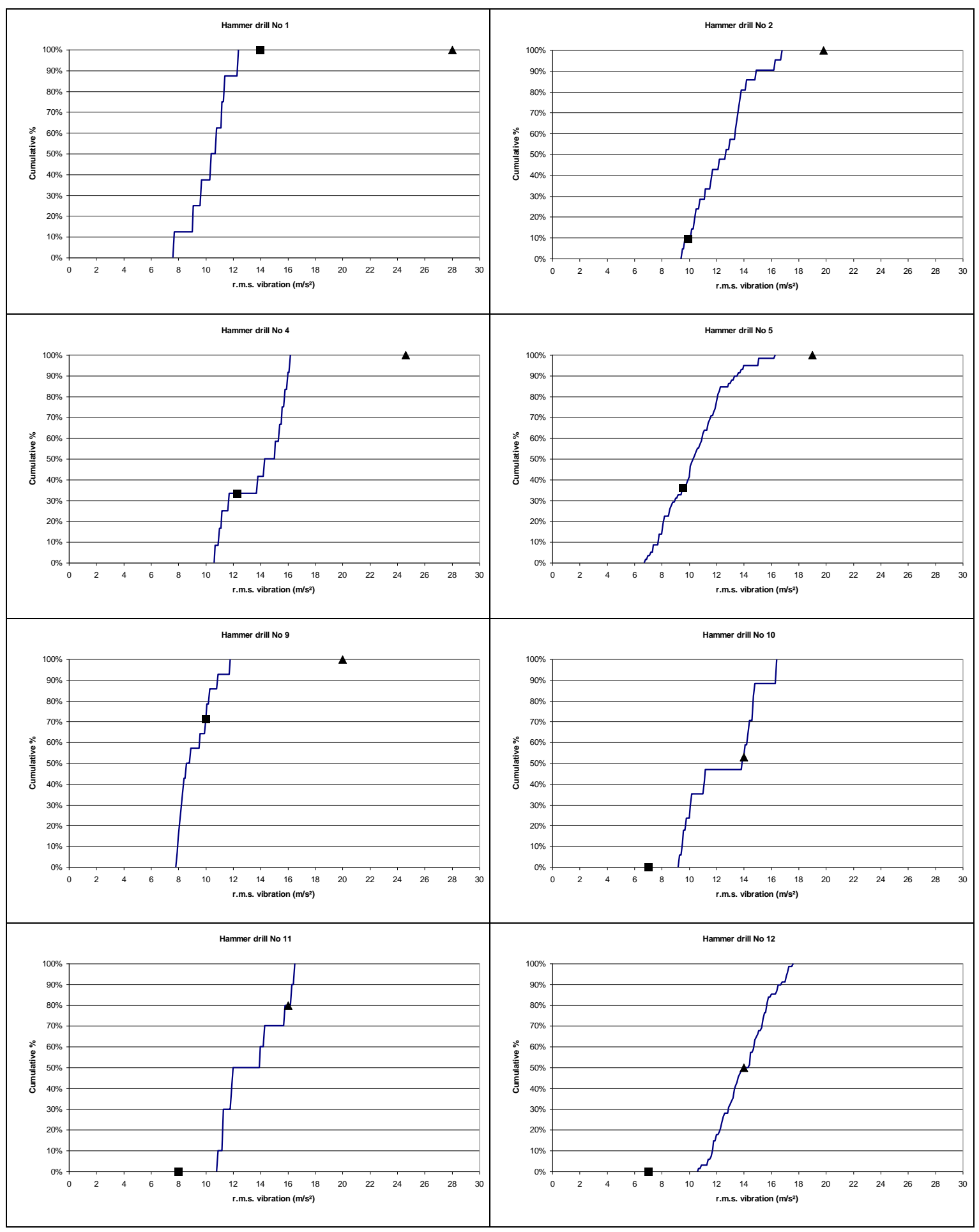

Figure 9: Cumulative histogram for measured data for eight hammer drills. Manufacturers' declared vibration exposure and adjusted declared vibration exposure (CEN/TR 15350 2006) are denoted by a square and a triangle respectively. 


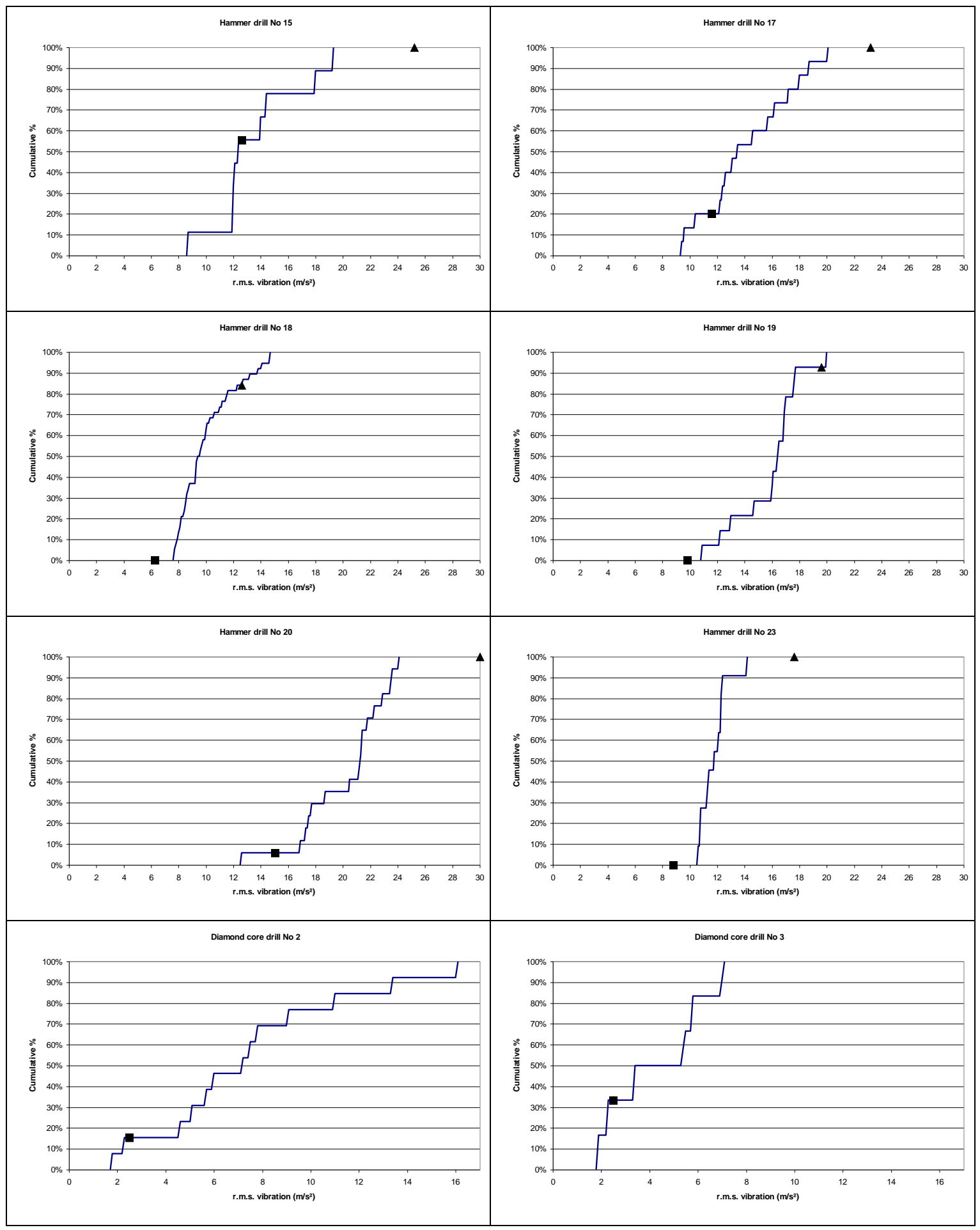

Figure 10: Cumulative histogram for measured data for six hammer drills and two diamond core drills. Manufacturers' declared vibration exposure and adjusted declared vibration exposure (CEN/TR 15350 2006) are denoted by a square and a triangle respectively. 


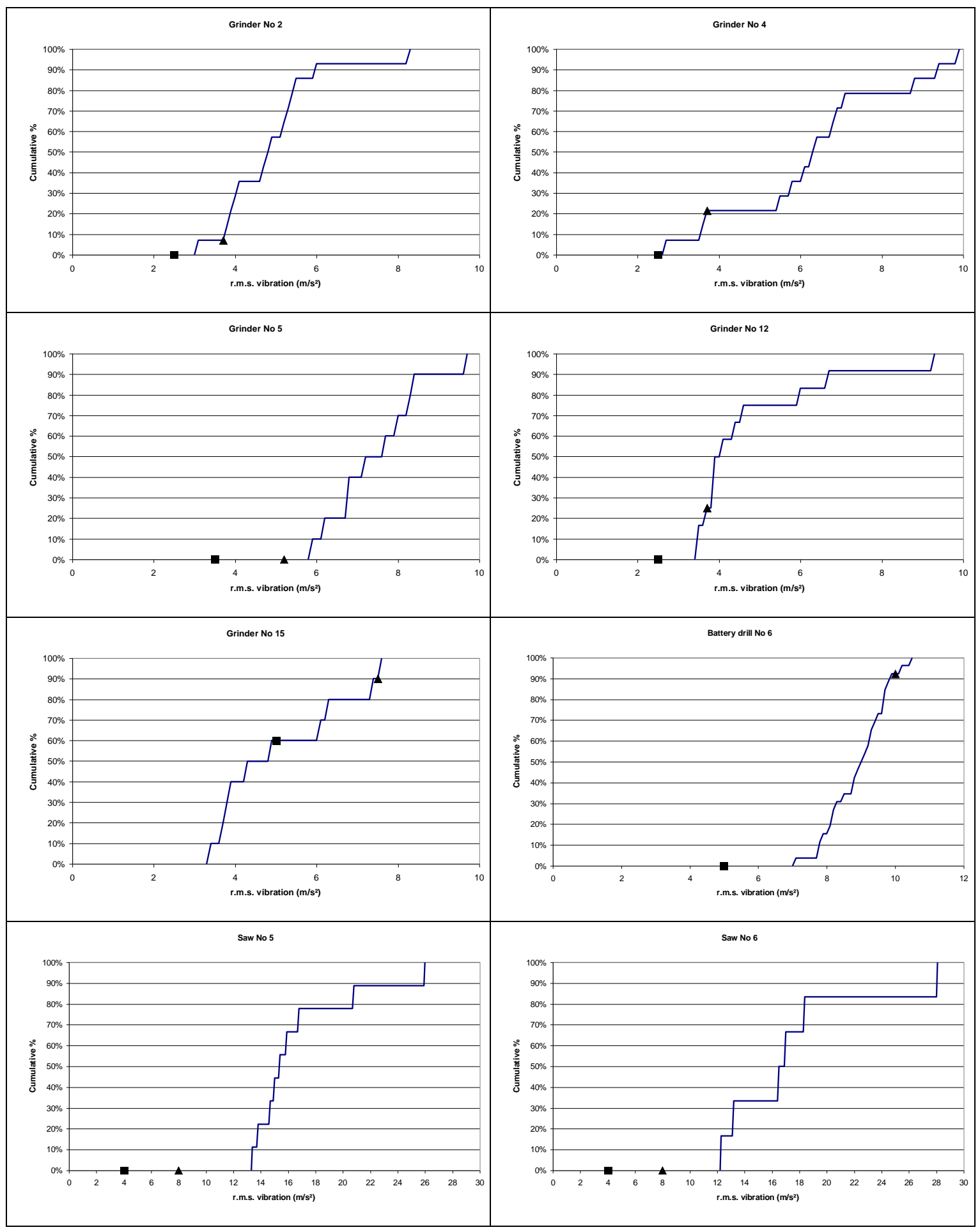

Figure 11: Cumulative histogram for measured data for five grinders, one battery powered drill and two saws. Manufacturers' declared vibration exposure and adjusted declared vibration exposure (CEN/TR 15350 2006) are denoted by a square and a triangle respectively. 


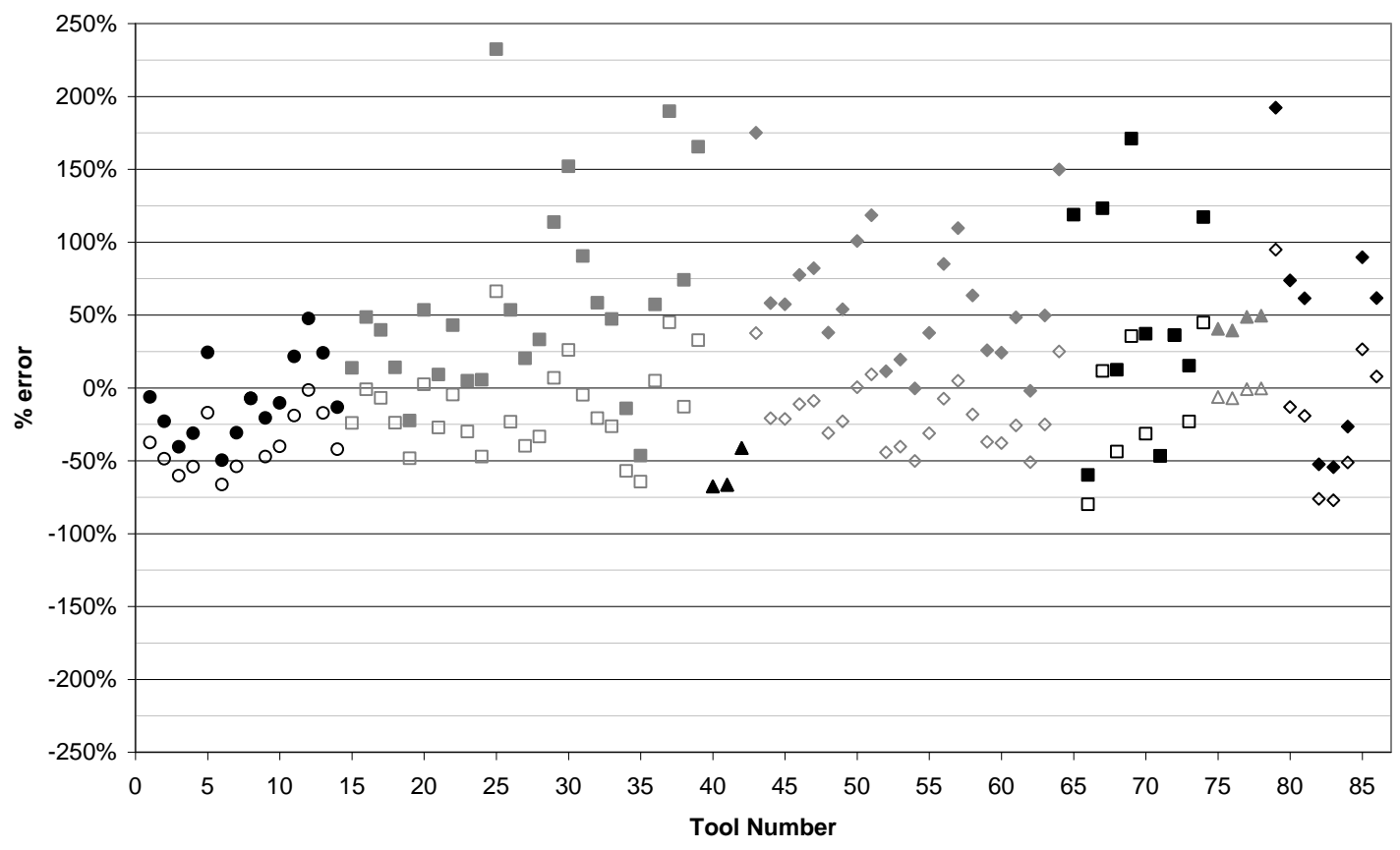

Figure 12: Percentage error in estimation of the mean vibration exposure for each tool from declared emission values (manufacturers' declared values denoted by open symbols and declared values adjusted according to CEN/TR 15350 (2006) denoted by solid symbols). Only the tools which have a declared value are shown (grinders [1-14], breakers [15-39], diamond core drills [4042], hammer drills [43-64], battery powered drills [65-74], sanders [75-78] and saws [79-86]). 


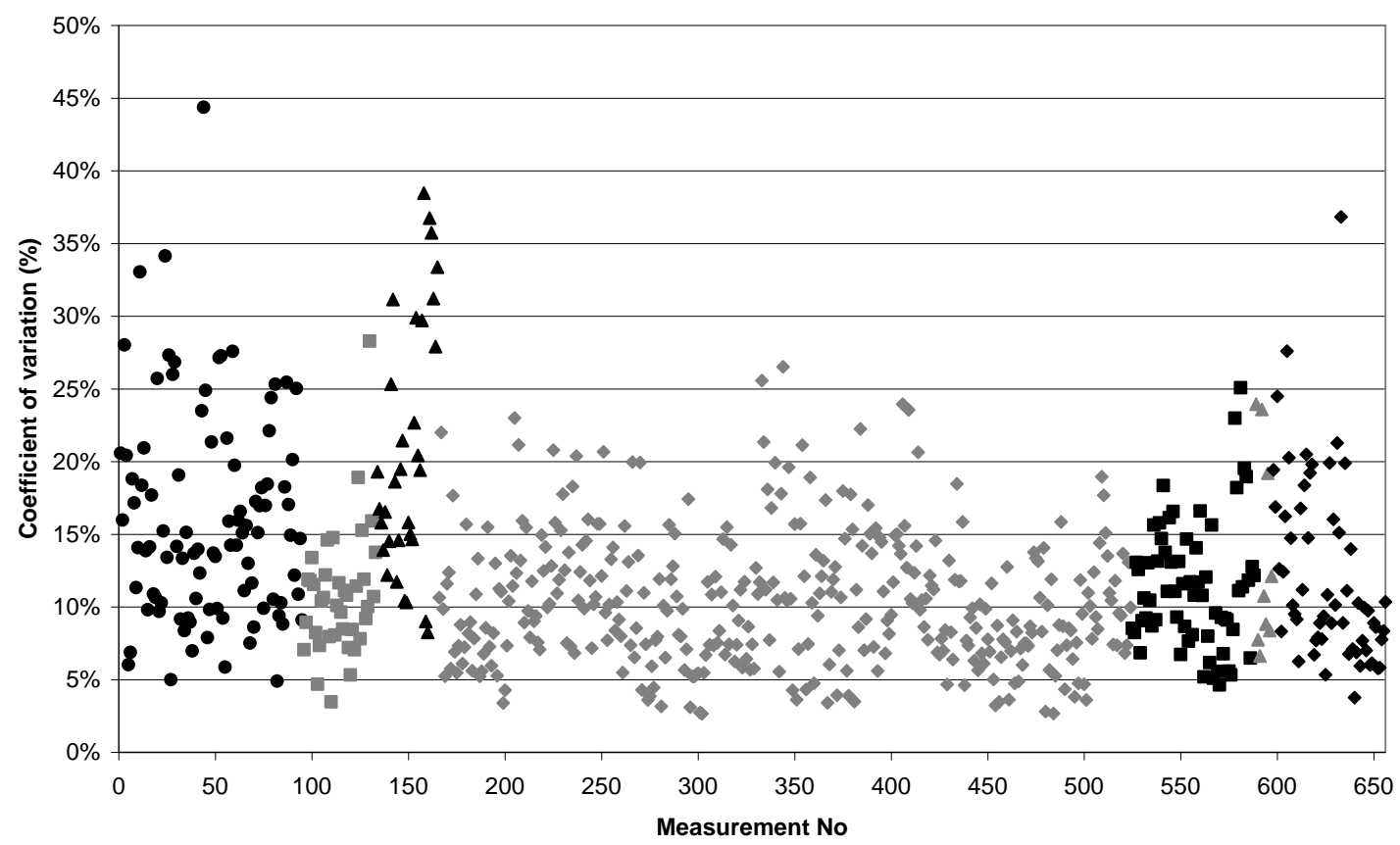

Figure 13: Coefficient of variation for all 656 measurements presented in this paper (the mean value is $12 \%$ ). Tests are for grinders [1-95], breakers [96-133], diamond core drills [134-165], hammer drills [166-524], battery powered drills [525-588], sanders [589-597] and saws [598-656]. 